\title{
Effect of Temporomandibular Joint Bony Ankylosis on Maxillary Sinus Wall Thickness
}

\author{
Dehis M. ${ }^{1}$, Tantawi W. ${ }^{2}$, Rasheed A. ${ }^{3}$ \\ ${ }^{1}$ Faculty of Oral \& Dental medicine, Cairo University, Cairo, Egypt \\ ${ }^{2}$ Faculty of Medicine, Ein Shams University, Cairo, Egypt \\ ${ }^{3}$ Faculty of Oral and Dental Medicine, Cairo University, Cairo, Egypt
}

Email address:

mesd47@gmail.com (Dehis M.), tantawyw@yahoo.com (Tantawi W.)dr.ahmedkamal83@hotmail.com (Rasheed A.)

*Corresponding author

\section{To cite this article:}

Dehis M., Tantawi W., Rasheed A. Effect of Temporomandibular Joint Bony Ankylosis on Maxillary Sinus Wall Thickness. International Journal of Clinical Oral and Maxillofacial Surgery. Vol. 2, No. 2, 2016, pp. 5-11. doi: 10.11648/j.ijcoms.20160202.11

Received: May 15, 2016; Accepted: June 3, 2016; Published: June 20, 2016

\begin{abstract}
Objectives: This study was designed to clarify the changes that might be induced in the maxillary sinus walls thickness in response to TMJ bony ankylosis Subjects and methods: Forty five (45) subjects were included in the study. They were divided into two groups Group I, (patients group) comprised fifteen 15 patients were suffering from temporomandibular joint bony ankylosis (26 maxillary sinuses involved) and Group II, (control group) contained thirty (30) healthy volunteer. Maxillary sinus walls thickness has been measured by computerized tomography scan for both groups and was compared. Results: There was significant increase in mean thickness of all walls of maxillary sinus in patients group. The thickness of lateral wall of recurrent cases of TMJ ankylosis showed significant decrease when compared with the non-recurrent cases. Conclusion: Observable Increase in the thickness of maxillary sinus walls. This may be attributed to bone apposition from outer side without resorption from inner side. This explanation is ascribed to lack of pneumatization associated with hindrance of upper air way that usually existing with cases of TMJ bony ankylosis.
\end{abstract}

Keywords: Temporomandibular Joint (TMJ) Ankylosis, Computerized Tomography, Maxillary Sinus Wall Thickness

\section{Introduction \& Review of Literature}

Temporomandibular joint (TMJ) ankylosis usually impairs the growth of lower jaw and lead to facial skeletal deformities. Review of literature showed that this subject its effect on maxillary sinus wall thickness has not investigated. This study was designed to clarify the changes that might be induced in the maxillary sinus walls thickness in response to TMJ bony ankylosis. The available researches were directed to study the lateral wall in procedure of sinus augmentation. The present study was intending to utilize the versatility of computed tomography (CT) to depict accurately the changes expected in the maxillary sinus walls thickness. CT plays an important role in the diagnosis and treatment of the TMJ ankylosis and paranasal sinuses due to its multiple advantages as compared with other conventional radiographic methods $[1,2]$.

Surgical correction of the residual facial deformities of
TMJ bony ankylosis is an important part and exceeds the significant release of the ankylosis itself. The present investigation can provide prediction for the possible changes of the maxillary sinus wall thickness. The gained information can assist in evaluation and surgical planning concerning the maxilla and hence the maxillary sinuses. The collected data in such group of patients will be of value in post ankylotic corrective maxillary orthognathic surgery.

The adult maxillary sinus is pyramidal in shape with its base represented as the lateral nasal wall and its apex extends into the body of zygomatic bone. It is bounded anteriorly by the outer wall of the maxilla and posteriorly by the infratemporal wall of maxilla. The floor of sinus is comprised of alveolar and palatine process of maxilla. The roof of maxillary sinus forms most of the orbital floor [3, 8]. The average volume of maxillary sinus in adult is $12-16 \mathrm{ml}$ and its average dimensions are $33 \mathrm{~mm}$ in height, $23-25 \mathrm{~mm}$ in width, and $34 \mathrm{~mm}$ in the anteroposterior axis [6, 9-14]. Evaluation the maxillary sinuses volume has been interested by many 
studies. Previous researchers measured the maxillary sinus volume on cadaveric materials, dry skulls, magnetic resonance images (MRI) and computed tomography (CT) scan [15-24].

The mean thickness of the lateral wall of maxillary sinus on cadavers was ranged from $1.23 \pm 0.78$ to $1.86 \pm 1.11 \mathrm{~mm}$ [25] and in other study has reported as $0.91 \pm 0.43 \mathrm{~mm}$ [26]. The mean thickness of the lateral wall of the maxillary sinus by $\mathrm{CT}$ assessment in edentulous patients from the first premolar to second molar was $1.69 \pm 0.71,1.50 \pm 0.72,1.77$ \pm 0.78 and $1.89 \pm 0.85 \mathrm{~mm}$, respectively [27] and other studies have reported the mean bony thickness of the posterolateral wall in children was $1.0 \pm 0.4 \mathrm{~mm}$ [28] and in adults was $1.03 \pm 0.16 \mathrm{~mm}$ [29]. Other study has reported the mean bony thickness of lateral wall was $0.98 \pm 0.2 \mathrm{~mm}$ (right) and $1.0 \pm 0.3 \mathrm{~mm}$ (left) [30].

The mean thickness of the lateral wall of the maxillary sinus by CBCT assessment in edentulous was $0.81 \pm 0.24$ to $2.88 \pm 0.56 \mathrm{~mm}$ and in dentate was $0.87 \pm 0.24$ to $3.03 \pm 0.53$ $\mathrm{mm}$ [31]. Other study has reported that the mean thickness of lateral wall have no significant difference with respect presence or absence of teeth [32].The mean thickness of maxillary sinus lateral wall of atrophic posterior maxilla by CBCT assessment for partial edentulous was $1.71 \pm 0.12 \mathrm{~mm}$ and for complete edentulous was $1.57 \pm 0.07 \mathrm{~mm}$ [33].

A significant correlation between sex and thickness of the lateral wall has been detected. A thicker wall was reported in male than female $[25,27,32,34]$. It has been reported that a significant correlation between age and lateral wall thickness in studies of $\mathrm{Li} \mathrm{j}$ et al [32] and Kang et al [34]. They indicated a thicker wall on older patients, however other studies reported no significant differences with age [25, 27]. No significant difference was declared between right and left side in the lateral wall thickness [25, 27]. It was pointed-out that the neighboring structures to maxillary sinus such as the zygomatic buttress, canine eminence and maxillary tuberosity might influence the thickness of the lateral wall of maxillary sinus $[25,26,31]$. The thinnest area of lateral wall was detected at interproximal region between second premolar and first molar, the thickest area was recorded at interproximal region between first and second molar [25].

The anterior wall thickness of the maxillary sinus was measured only by CT scans. The mean value of the bony anterior wall of the maxillary sinus in patients with normal mid-face region at the canine fossa was $1.1 \mathrm{~mm}$ [9]. Other study has revealed $1.10 \pm 0.16 \mathrm{~mm}$ thicknesses [29].

\section{Subjects \& Methods}

The present study comprised forty five (45) subjects. They were selected from those attending the outpatient clinic, Department of Oral and Maxillofacial Surgery, Faculty of Oral and Dental Medicine, Cairo University. They have been classified into two groups:

Group I, (patients group) comprised fifteen 15 patients (26 sinuses) suffering from temporomandibular joint bony ankylosis (TMJBA) with mean of age (23.267 years) and duration mean 12.73 years. Eleven patients had bilateral TMJ bony ankylosis (22 sinuses) and four cases had unilateral bony ankylosis (4 sinuses). Unilateral cases were on left side. Medically compromised patients, cases of fibrous and extra articular ankylosis, syndromic diseases involving the joint ex. Ankylosing spondylitis bone diseases and lesions involving maxillary sinuses were excluded according from the study.

Group II, (control group) comprised thirty (30) healthy volunteer subjects with mean of age (24.033 years). They have been obtained from patients with other medical condition in whom no abnormalities of the maxillary sinus were detected. Consequently CT was not performed particularly for the maxillary sinus to avoid extra radiation hazard. The procedures have been explained and their consent has been obtained.

The patients group (group I) were distributed by median into 2 subgroups according to the duration of ankylosis (subgroup D1 and D2) where subgroup D1 (13sinuses) with duration up to 10 years. While in subgroup D 2 (13 sinuses) with duration more than 10 years. They were distributed also according to recurrence of ankylosis into (subgroup R1and R2) where R1 (12 sinuses) non-recurrent case and subgroup R2 (14 sinuses) recurrent cases.

All the subject in group I and II were subjected to computerized Tomography (CT) of the facial skeleton (coronal, axial and 3D reconstruction) (Fig. 1) for assessment of the maxillary sinus wall thickness. All the computed tomography (CT) examinations were done with a slice multidetector (CT) scanner (Toshiba, Aquillion 64, Japan). Scanning was performed in the standard axial plane with the helical technique (a FOV of $18 \mathrm{~cm}$, a pitch of 0.562 , a rotation time of $0.35 \mathrm{sec}$, a section thickness of $0.5 \mathrm{~mm}$ and a matrix of $512 \times 512$ ). The subjects were scanned in a supine position to obtain image plane parallel to the Frankfurt plane. All the image data sets were transferred from the CT scanner to personal computer work station, and the data sets were analyzed using $3 \mathrm{D}$ medical imaging software (on vitra work station).
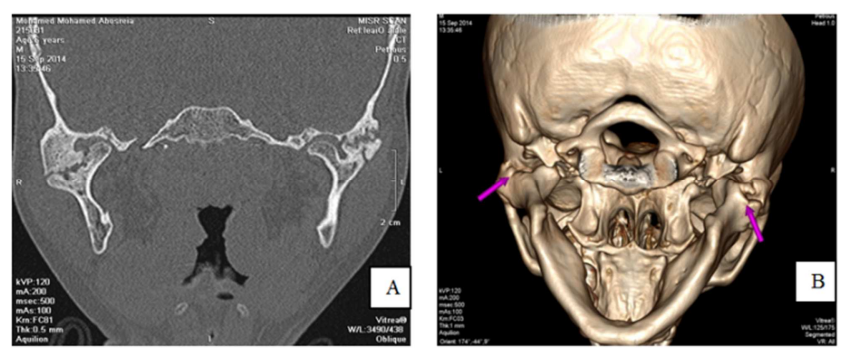

Fig. 1. (A) Coronal cut CT \&, (B) 3D CT bilateral TMJ bony ankylosis, case number 7 .

Assessment of the Maxillary Sinus Wall Thickness:

The coronal cut of CT scans was used to locate infraorbital foramen (IOF). The selected axial cut of CT for this study was chosen at level of $10 \mathrm{~mm}$ below infra-orbital foramen (Fig.2). Three steps have been carried out to determine reproducible points for location of different walls of maxillary sinus: 

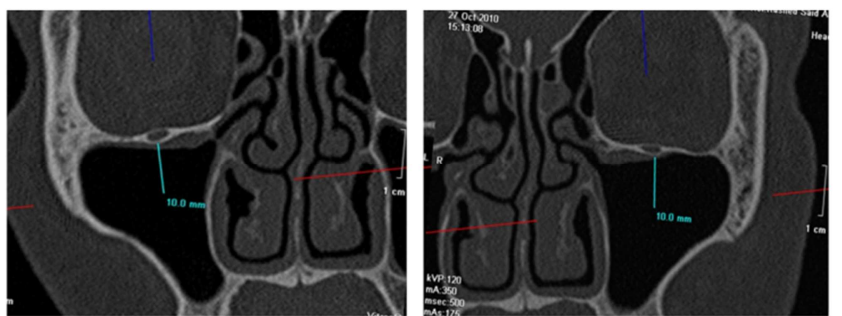

Fig. 2. coronal cuts of right and left sides [Red Lines] as used as guides to select levels of the axial cuts, case number 4.

Step1: Reference Points for Determination of Radiographic Walls of the Maxillary Sinus:

At the selected axial cut: Four reference points (A, B, C \& D) were determined from inner side of maxillary sinus (Fig.3). Points were allocated as:

Points Description

A Deepest point of meeting anterior wall with lateral wall

B Deepest point of meeting of anterior wall with medial wall

C Deepest point of meeting of medial wall with posterior wall

D Deepest point of meeting of lateral wall with posterior wall

These points determine the anterior, lateral, medial and posterior walls of maxillary sinus by connecting lines.

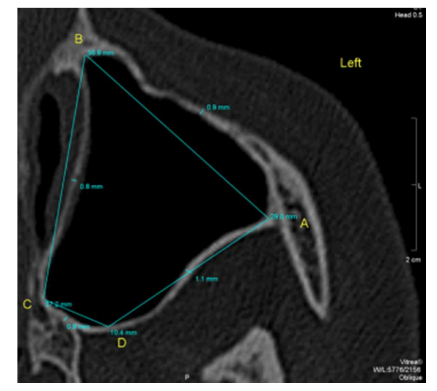

Fig. 3. axial cut with reference points (A, B, C\&D), ankylosis case number 4.

Step 2: Radiographic Definition of Walls of Maxillary Sinus on the Axial Cuts (Fig. 3):

Line Definition of wall

$\mathrm{AB} \quad$ The anterior wall

BC The medial wall

CD The posterior wall
AD The lateral wall

Step 3: Determination of Reference Points for Measurements of Thickness: (Fig. 4).

The thickness of maxillary sinus walls at selected axial cut is represented by points of intersection of the perpendicular line from:

$\begin{array}{ll}\text { Wall thickness } & \begin{array}{l}\text { Points of intersection of the } \\ \text { perpendicular line }\end{array} \\ \text { Anterior (TAW) } & \text { From mid AB line } \\ \text { Medial (TMW) } & \text { From mid BC line } \\ \text { Lateral (TLW) } & \text { From mid AD line } \\ \text { Posterior (TPW) } & \text { From mid CD line }\end{array}$

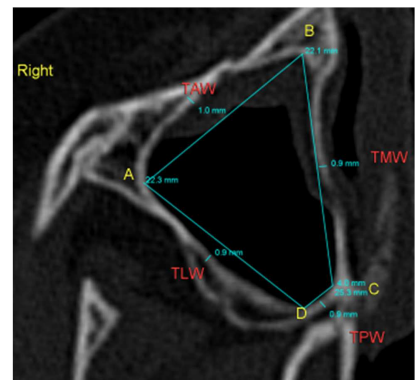

Fig. 4. axial cut with reference points for thickness (TAW, TMW, TPW \& $T M W)$, ankylosis case number 11.

The data were collected and tabulated, descriptive and analytical statistics using Statistical Package for Social Sciences (SPSS) version 21, 2013. Comparison was carried out between patient and control group, also between bilateral ankylosis cases and control group as well as between subgroups among the cases of ankylosis. Student test were used (t-paired) for evaluation of the changes occurring in thickness of maxillary sinus walls. P value was significance $\leq$ 0.05 .

\section{Results}

1) Comparison between maxillary sinus walls thickness in patients group and control group:

On comparison between the mean thickness of the anterior (TAW), medial (TMW), lateral (TLW) and posterior (TPW) walls of maxillary sinus in patients and control group there were an increase in mean thickness of all walls of patients group. This increase was statistically significant with P-value $(<0.05)$. (Table 1 - Fig, 5)

Table 1. Statistical comparison of the maxillary sinus walls thickness between patients and control group.

\begin{tabular}{lllllll}
\hline & \multicolumn{2}{l}{ Patients group } & & \multicolumn{2}{c}{ Control Group } & \multicolumn{2}{c}{ t-test for Equality of Means } \\
\cline { 2 - 6 } & Mean & Std. Dev. & Mean & Std. Dev. & t \\
\hline TAW & 0.9346 & 0.17876 & 0.14967 & 0.58 & 0.09708 & 11.892 \\
TMW & 0.8 & 0.16715 & 0.5567 & 0.08707 & $<0.0001$ \\
TLW & 0.8923 & 0.13132 & 0.5617 & 0.09405 & $<64$ \\
TPW & 0.7731 & 0.5217 & 0.08045 & 11.684 & 10.884 \\
\hline
\end{tabular}

*Thickness of Anterior Wall

**Thickness of Medial Wall

***Thickness of Lateral Wall

****Thickness of Posterior Wall 


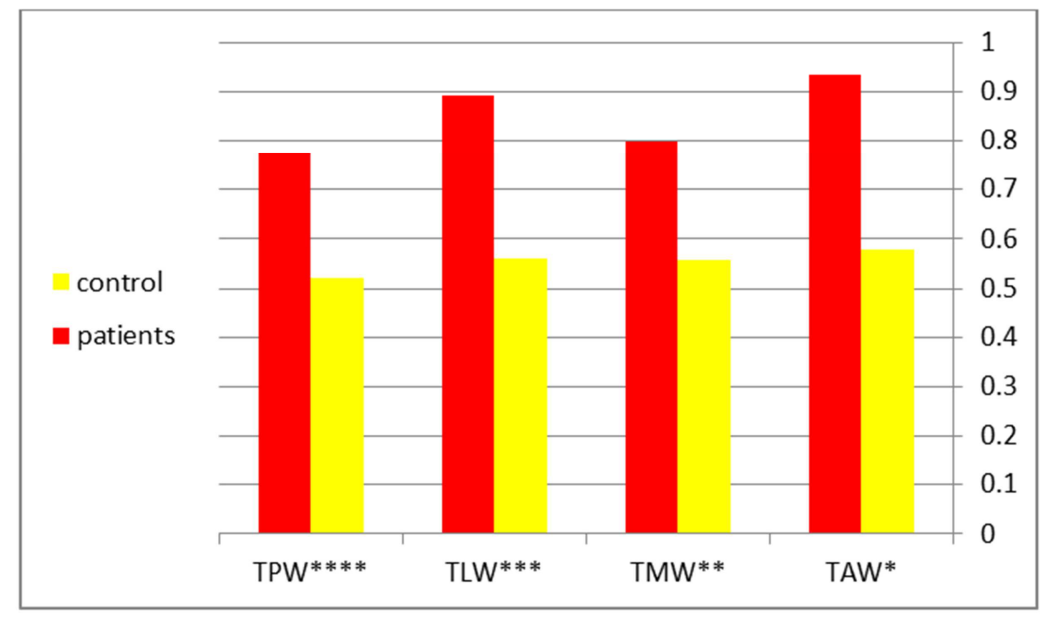

Fig. 5. Mean thickness of maxillary sinus walls in patients and control groups.

2) Comparison of the maxillary sinus walls thickness in bilateral ankylotic joint and control group:

On comparison between the mean thickness of the anterior (TAW), medial (TMW), lateral (TLW) and posterior (TPW) walls of maxillary sinus in patients with bilateral ankylosis and control group it was detected that there were an increase in mean thickness of the patients with bilateral ankylosis. This increase is statistically significant with P-value $(<0.05)$. (Table 2 - Fig. 6)

Table 2. Statistical comparison of the maxillary sinus walls thickness between bilateral ankylosis and control group.

\begin{tabular}{|c|c|c|c|c|c|c|}
\hline & \multicolumn{2}{|c|}{ Bilateral ankylosis } & \multicolumn{2}{|c|}{ Control Group } & \multicolumn{2}{|c|}{ t-test for Equality of Means } \\
\hline & Mean & Std. Dev. & Mean & Std. Dev. & t & P-value \\
\hline TAW $^{*}$ & 0.9318 & 0.15852 & 0.58 & 0.09708 & 12.128 & $<0.0001$ \\
\hline $\mathrm{TMW}^{* *}$ & 0.7909 & 0.11088 & 0.5567 & 0.08707 & 10.008 & $<0.0001$ \\
\hline $\mathrm{TLW}^{* * *}$ & 0.8727 & 0.15791 & 0.5617 & 0.09405 & 10.917 & $<0.0001$ \\
\hline $\mathrm{TPW}^{* * * *}$ & 0.7727 & 0.11622 & 0.5217 & 0.08045 & 11.044 & $<0.0001$ \\
\hline
\end{tabular}

*Thickness of Anterior Wall

**Thickness of Medial Wall

***Thickness of Lateral Wall

****Thickness of Posterior Wall

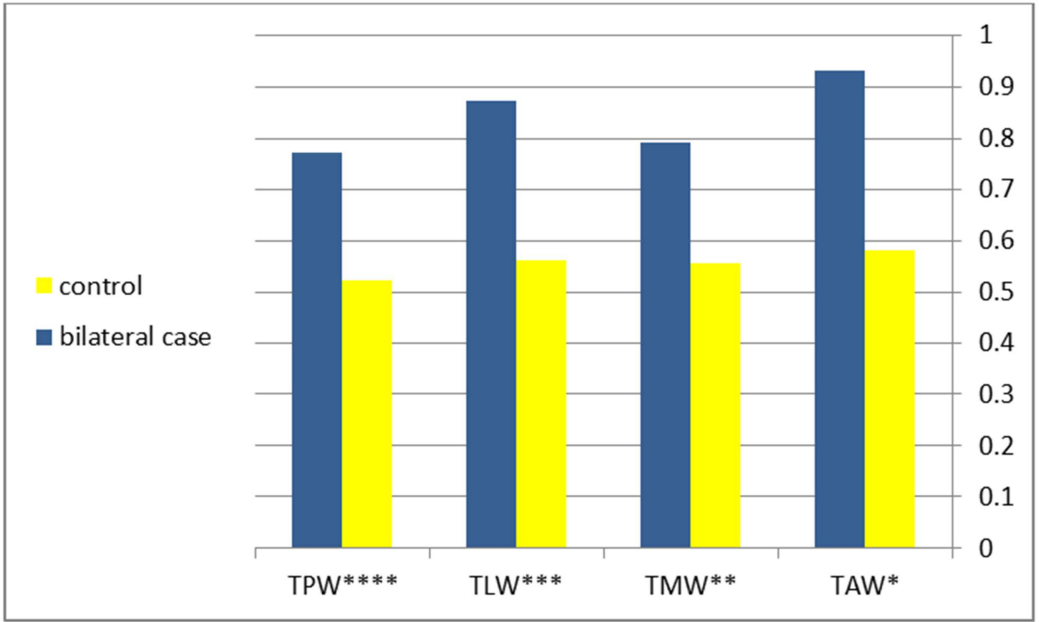

Fig. 6. Mean thickness of MS walls in bilateral ankylosis and control groups.

3) Effects of the duration and recurrence of TMJ ankylosis on the maxillary sinus walls thickness.

On comparison between the mean thickness of the anterior (TAW), medial (TMW), lateral (TLW) and posterior (TPW) walls of maxillary sinus in two subgroups of duration (D1: up to 10 years and D2: more than 10 years) and in two subgroups of recurrence (non-recurrent and recurrent) they showed no statistical significant difference except for the lateral wall in subgroups of recurrence that showed statistically significant difference (Table 3, 4 and Fig. 7) 
Table 3. Statistical comparison between subgroup D1and D2 as regard effect of the duration of TMJ on the maxillary sinus walls thickness.

\begin{tabular}{|c|c|c|c|c|c|c|}
\hline & \multicolumn{2}{|c|}{ Duration of ankylosis up to 10 years (D1) } & \multicolumn{2}{|c|}{ Duration of ankylosis more than 10 years (D2) } & \multicolumn{2}{|c|}{ t-test for Equality of Means } \\
\hline & Mean & Std. Dev. & Mean & Std. Dev. & $\mathbf{t}$ & P-value \\
\hline TAW & 0.9308 & 0.20569 & 0.9385 & 0.15566 & -0.108 & 0.915 \\
\hline TMW & 0.8462 & 0.18536 & 0.7538 & 0.08771 & 1.623 & 0.118 \\
\hline TLW & 0.9154 & 0.16251 & 0.8692 & 0.17505 & 0.697 & 0.493 \\
\hline TPW & 0.7615 & 0.15566 & 0.7846 & 0.10682 & -0.441 & 0.663 \\
\hline
\end{tabular}

*Thickness of Anterior Wall

**Thickness of Medial Wall

***Thickness of Lateral Wall

$* * * *$ Thickness of Posterior Wall

Table 4. Statistical comparison of the walls thickness of maxillary sinus between fresh and recurrent cases.

\begin{tabular}{lll|llll}
\hline & fresh ankylosis & & Recurrent ankylosis & & t-test for Equality of Means \\
\cline { 2 - 6 } & Mean & Std. Dev. & Mean & Std. Dev. & t \\
\hline TAW & 0.975 & 0.17123 & 0.9 & 0.18397 & 1.07 \\
TMW & 0.8417 & 0.1832 & 0.7643 & 0.10818 & 1.335 \\
TLW & 0.9917 & 0.13114 & 0.8071 & 0.14917 & 3.322 \\
TPW & 0.7917 & 0.1505 & 0.7571 & 0.11579 & 0.195 \\
\hline
\end{tabular}

*Thickness of Anterior Wall

**Thickness of Medial Wall

****Thickness of Lateral Wall

****Thickness of Posterior Wall

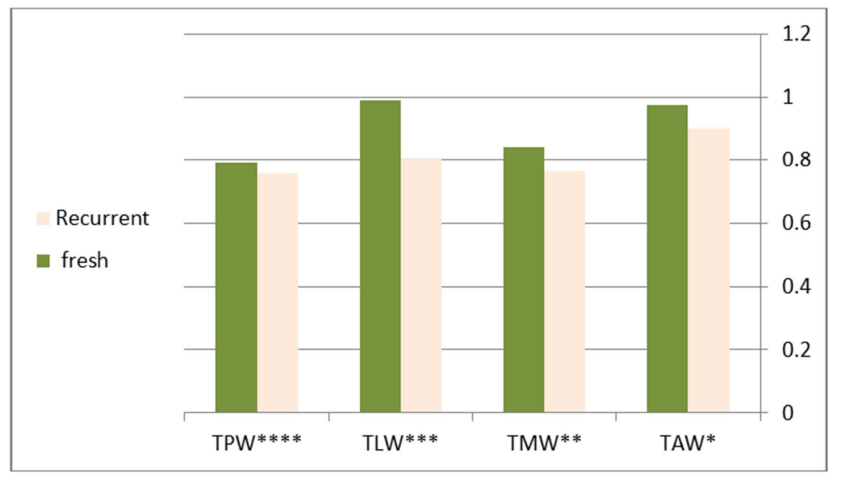

Fig. 7. Mean thickness of MS Walls in subgroup fresh and recurrent.

\section{Discussion}

The present study was directed to assess the effect of temporomandibular joint bony ankylosis on the wall thickness of the maxillary sinus. This study in normal and abnormal subjects is demanded in the specialty of the oral and maxillofacial surgery. The skeletal deformities associated with TMJ bony ankylosis are not limited to the lower jaw; but it extends also to involve the rest of facial skeleton. The induced anatomical variations in the maxillary sinus due to ankylosis must be identified prior to dental implant, posterior maxillary dentoalveolar surgery and maxillary orthognathic surgery to avoid complications. The obtained data will enrich the field of oral and maxillofacial surgery and help post ankylotic maxillary orthognathic surgery. Review of literature in this subject has revealed that the bony walls thickness of maxillary sinus have not received the necessary attention. The reported studies were directed to explore the lateral wall for procedure of sinus augmentation and in the field of otolaryngology it was directed to evaluate the changes in the bony thickness in response to chronic rhinosinusitis.

The measurement obtained by computed tomography scans, whether two dimensional (2D) or three dimensional (3D) are considered reliable and accurate and match the measurement obtained by skull osteometry. These findings were supported by many authors $[9,11,16,19,24,29,35-$ 41]. In this study the mid region of the maxillary sinus has been selected as a site for wall thickness assessment being clear with no masking structures as zygomatic complex and infraorbital buttress. The adjacent structures might influence the accuracy of the topographical imaging of maxillary sinus.

The infraorbital foramen has been utilized as reproducible reference point being the most reliable landmark. This opinion is reinforced by studies of Cho et al [29] and Sahlstrand et al [9]. The axial cuts of CT scans have been selected for measurement being an original cut not reformatted in CT scans and the four walls of sinus are evident without superimposition. This opinion is supported by previous studies of Cho, et al [29], Sahlstrand et al [9] Kim et al [28] and Joshua, et al [42].

Temporomandibular joint bony ankylosis induces secondary changes in the maxilla affecting its size. This ascribed to lake a secondary or a compensatory response to the requirement of the soft tissue functions i.e. these findings could be attributed to lack of functional stimuli transmitted from the mandible to maxillary bone either through articulation with temporomandibular joint or due to lack of chewing and masticatory stimuli.

Expansion of maxillary sinus starts by growth of the maxilla in general; by eruption of maxillary teeth and by bone resorption induced by pneumatization process from inside and bone formation incited by muscles activity from outside. Lack of growth of maxillary sinus in patients of TMJ ankylosis can be attributed to lack of pneumatization and lack of growth of the Mandible this explanation is supported by other authors [43-46]. It has been reported that there was affection of upper airway in patients of TMJ ankylosis. It was 
represented by upward and backward position of tongue [43] and hyoid bone [44], marked diminution in upper airway [45], hence marked reduction of volume of maxillary sinus [46]. So, increase thickness of walls of maxillary sinus in the present study can be ascribed to lack of pneumatization which is part of upper airway involvement.

Reduction of maxillary sinus volume was reported among patients of temporomandibular joint bony ankylosis by Dehis, and associates [46]. Increase in the thickness of walls may be attributed to this reduction of volume which is expressed in the form of bone apposition from outer side without resorption from inner side. This explanation is ascribed to lack of pneumatization associated with hindrance of upper air way and usually existing with cases of TMJ bony ankylosis as reported in previous studies [43-45].

\section{References}

[1] Jagannathan M: Temporomandibular joint ankylosis. Indian J Plast Surg. 2009; 42:187-8.

[2] Vasconcelos BC, Bessa-Nogueira RV, \& Cypriano RV: Treatment of temporomandibular joint ankylosis by gap arthroplasty. Med Oral Patol Oral Cir Bucal. 2006; 11: 66-9.

[3] Hamilton, WJ \& Harrison, RJ: The nose, nasal cavity and paranasal sinuses. In: Scott-Brown W.G., editor. Diseases of the ear nose and throat. London: Butterworth; 1952; pp. 16-20.

[4] Lund VJ: Anatomy of the nose and paranasal sinuses. In: Kerr A.G., editor. Scott Brown's Otolaryngology. 6. London: Butterworth Heinemann; 1997; pp. 1/5/1-1/5/29.

[5] Anagnostopoulou S, Venieratos D\& Spyropoulos N: Classification of human maxillary sinuses according to their geometric features. Anat Anz. 1991; 173: 121-30.

[6] Karmody CS, Carter B, \&Vincent ME: Developmental anomalies of the maxillary sinus. Trans Sect Otolaryngol Am Acad Ophthalmol Otolaryngol. 1977; 84: 723-8.

[7] Mc Growan DA, Baxter PW \& James J: The Maxillary Sinus and its Dental Implications. 1st ed. London: Wright Co; 1993; pp. $1-25$.

[8] Hamdy RM, \& Abdel-Wahed N: Cone-beam computed tomographic volumetric analysis of the maxillary antra for sinus augmentation. Egypt Dent J. 2012; 58: 3157-3165.

[9] Sahlstrand-Johnson P, Jannert M, Strömbeck A, \&Abul-Kasim $\mathrm{K}$ : Computed tomography measurements of different dimensions of maxillary and frontal sinuses. BMC Med Imaging. 2011; 11: 8 .

[10] Ariji Y, Kuroki T, Moriguchi S, Ariji E, \&Kanda S: Age changes in the volume of the human maxillary sinus: a study using computed tomography. Dentomaxillofac Radiol. 1994; 23: $163-8$.

[11] Ariji Y, Ariji E, Yoshiura K, \& Kanda S. Computed tomographic indices for maxillary sinus size in comparison with the sinus volume. Dentomaxillofac Radiol. 1996; 25: 19-24.

[12] Hamdy RM, \& Abdel-Wahed N: Three-dimensional linear and volumetric analysis of maxillary sinus pneumatization. J Adv
Res. 2014; 5: 387-95.

[13] Tiwana, PS, Kushner GM, \& Haug RH: Maxillary sinus augmentation. Dent Clin North Am. 2006; 50:409-24.

[14] Shahbazian M, Xue D, Hu Y, van Cleynenbreugel J, \& Jacobs R: Spiral computed tomography based maxillary sinus imaging in relation to tooth loss, implant placement and potential grafting procedure. J Oral Maxillofac Res. 2010; 1: 7.

[15] Wolf G, Anderhuber W, \& Kuhn F: Development of the paranasal sinuses in children: implications for paranasal sinus surgery. Ann Otol Rhinol Laryngol.1993; 102: 705-11.

[16] Uchida Y, Goto M, Katsuki T, \& Akiyoshi T: A cadaveric study of maxillary sinus size as an aid in bone grafting of the maxillary sinus floor. J Oral Maxillofac Surg. 1998; 56: 115863.

[17] Japanese Society of Pediatric Dentistry: A study on the cephalometric standards of Japanese children. Jpn J Ped Dent.1995; 33: 659-96.

[18] Barghouth G, Prior JO, Lepori D, Duvoisin B, Schnyder P, \& Gudinchet F: Paranasal sinuses in children: size evaluation of maxillary, sphenoid, and frontal sinuses by magnetic resonance imaging and proposal of volume index percentile curves. Eur Radiol. 2002; 12: 1451-8.

[19] Emirzeoglu M, Sahin B, Bilgic S, Celebi M, \& Uzun A:Volumetric evaluation of the paranasal sinuses in normal subjects using computer tomography images: a stereological study. Auris Nasus Larynx. 2007; 34: 191-5.

[20] Jun BC, Song SW, Park CS, Lee DH, Cho KJ, \&Cho JH: The analysis of maxillary sinus aeration according to aging process; volume assessment by 3-dimensional reconstruction by highresolutional CT scanning. Otolaryngol Head Neck Surg. 2005; 132: 429-34.

[21] Basdra EK, Stellzig A, \& Komposch G: The importance of the maxillary sinuses in facial development: a case report. Eur J Orthod. 1998; 20: 1-4.

[22] Koppe T, Weigel C, Bärenklau M, Kaduk W, Bayerlein T, \& Gedrange T: Maxillary sinus pneumatization of an adult skull with an untreated bilateral cleft palate. J Craniomaxillofac Surg. 2006; 34: 91-5.

[23] Suzuki H, Yamaguchi T, \& Furukawa M: Rhinologic computed tomographic evaluation in patients with cleft lip and palate. Arch Otolaryngol Head Neck Surg. 1999; 125: 1000-4.

[24] Pirner S, Tingelhoff K, Wagner I, Westphal R, Rilk M, Wahl FM, Bootz F, \& Eichhorn KW: CT-based manual segmentation and evaluation of paranasal sinuses. Eur Arch Otorhinolaryngol. 2009; 266: 507-18.

[25] Yang HM, Bae HE, Won SY, Hu KS, Song WC, Paik DJ, \& Kim HJ: The buccofacial wall of maxillary sinus: an anatomical consideration for sinus augmentation. Clin Implant Dent Relat Res. 2009; 11: 2-6.

[26] Neiva RF, Gapski R, \& Wang HL: Morphometric analysis of implant-related anatomy in Caucasian skulls. J Periodontol. 2004; 75: 1061-7.

[27] Yang SM, Park SI, Kye SB, \& Shin SY: Computed tomographic assessment of maxillary sinus wall thickness in edentulous patients. J Oral Rehabil. 2012; 39: 421-8. 
[28] Kim HY, Kim MB, Dhong HJ, Jung YG, Min JY, Chung SK, Lee HJ, Chung SC, \& Ryu NG: Changes of maxillary sinus volume and bony thickness of the paranasal sinuses in longstanding pediatric chronic rhinosinusitis. Int $\mathrm{J}$ Pediatr Otorhinolaryngol.2008; 72: 103-8.

[29] Cho SH, Kim TH, Kim KR, Lee JM, Lee DK, Kim JH, Im JJ, Park CJ, \& Hwang KG: Factors for maxillary sinus volume and craniofacial anatomical features in adults with chronic rhinosinusitis. Arch Otolaryngol Head Neck Surg. 2010; 136: $610-5$.

[30] Deeb R, Malani PN, Gill B, Jafari-Khouzani K, SoltanianZadeh H, Patel S, \& Zacharek MA: Three-dimensional volumetric measurements and analysis of the maxillary sinus. Am J Rhinol Allergy. 2011; 25: 152-6.

[31] Khajehahmadi S, Rahpeyma A, \& Hoseini Zarch SH: Association between the lateral wall thickness of the maxillary sinus and the dental status: cone beam computed tomography evaluation. Iran J Radiol. 2014; 11: 6675.

[32] Li J, Zhou ZX, Yuan H, Shen M, Sun C, \& Chen N: A study of maxillary sinus lateral wall thickness of Han population in Jiangsu region using cone-beam CT. Shanghai Kou Qiang Yi Xue. 2013; 22: 537-41

[33] Monje A, Catena A, Monje F, Gonzalez-García R, GalindoMoreno P, Suarez F, \& Wang HL: Maxillary sinus lateral wall thickness and morphologic patterns in the atrophic posterior maxilla. J Periodontol. 2014; 85:76-82.

[34] Kang SJ, Shin SI, Herr Y, Kwon YH, Kim GT, \& Chung JH: Anatomical structures in the maxillary sinus related to lateral sinus elevation: a cone beam computed tomographic analysis. Clin Oral Implants Res. 2013; 24: 75-81.

[35] Brough AL, Bennett J, Morgan B, Black S, \& Rutty GN: Anthropological measurement of the juvenile clavicle using multi-detector computed tomography - affirming reliability. J Forensic Sci. 2013; 58: 946-51.

[36] Hildebolt CF, Vannier MW, \& Knapp RH: Validation study of skull three-dimensional computerized tomography measurements. Am J Phys Anthropol. 1990; 82: 283-94.

[37] Lopes PM, Moreira CR, Perrella A, Antunes JL, \& Cavalcanti
MG: 3-D volume rendering maxillofacial analysis of angular measurements by multislice CT. Oral Surg Oral Med Oral Pathol Oral Radiol Endod. 2008; 105: 224-30.

[38] Stull KE, Tise ML, Ali Z, \& Fowler DR: Accuracy and reliability of measurements obtained from computed tomography 3D volume rendered images. Forensic Sci Int. 2014; 238: 133-40.

[39] Williams FL, \& Richtsmeier JT: Comparison of mandibular landmarks from computed tomography and 3D digitizer data. Clin Anat. 2003; 16:494-500.

[40] Lou L, Lagravere MO, Compton S, Major PW, \& Flores-Mir $\mathrm{C}$ : Accuracy of measurements and reliability of landmark identification with computed tomography techniques in the maxillofacial area: a systematic review. Oral Surg Oral Med Oral Pathol Oral Radiol Endod. 2007; 104: 402-11.

[41] Jóźwiak M, Rychlik M, Musielak B, Chen BP, Idzior M, \& Grzegorzewski A: An accurate method of radiological assessment of acetabular volume and orientation in computed tomography spatial reconstruction. BMC Musculoskelet Disord. 2015; 16: 42.

[42] Joshua BZ, Sachs O, Shelef I, Vardy-Sion N, Novack L, Vaiman M, \& Puterman M: Comparison of clinical data, CT, and bone histopathology in unilateral chronic maxillary sinusitis. Otolaryngol Head Neck Surg. 2013; 148: 145-50.

[43] Kamal A: Effect of gap-arthroplasty on the tongue position in patients of temporomandibular joint ankylosis. (Master Dissertation) Cairo University. Egypt; 1999: Page 93.

[44] Khedr H: Effect of gap-arthroplasty on the position of hyoid bone in patients suffering from temporomandibular joint ankylosis. (Master Dissertation) Cairo University. Egypt; 2001: Page 99.

[45] Alaa MA: Effect of gap-arthroplasty on the upper airway in patients of temporomandibular joint ankylosis. (Master Dissertation) Cairo University. Egypt; 2000: Page 82.

[46] Dehis M, Tantawi W, Kamal A, \& Atta M: Assessment of maxillary sinus volume in patients of temporomandibular joint bony ankylosis. International Clinical Oral and Maxillofacial Surgery. 2015; 1: 24-30. 